\title{
Correction to: Sterigmatocystin moderately induces oxidative stress in male Wistar rats after short-term oral treatment
}

\author{
Dubravka Rašić ${ }^{1}$ - Daniela Jakšić ${ }^{2}$. Andrea Hulina Tomašković ${ }^{3}$ - Domagoj Kifer ${ }^{4}$. Nevenka Kopjar ${ }^{5}$ - Lada Rumora ${ }^{3}$. \\ Davor Želježić ${ }^{5}$ Maja Peraica ${ }^{1} \cdot$ Maja Šegvić Klarić ${ }^{2}$ (1)
}

Published online: 27 November 2020

(C) Society for Mycotoxin (Research Gesellschaft für Mykotoxinforschung e.V.) and Springer-Verlag GmbH Germany, part of Springer Nature 2020

\section{Correction to: Mycotoxin Research (2020) 36:181-191. https://doi.org/10.1007/s12550-019-00382-8}

The original version of this article unfortunately contained a mistake. The author's first and last names were interchanged in the published version of this article. The corrected author names are given in this article.

Publisher's note Springer Nature remains neutral with regard to jurisdictional claims in published maps and institutional affiliations.

The online version of the original article can be found at https://doi.org/ $10.1007 / \mathrm{s} 12550-019-00382-8$

Maja Šegvić Klarić

msegvic@pharma.hr

1 Toxicology Unit, Institute for Medical Research and Occupational Health, Zagreb, Croatia

2 Department of Microbiology, Faculty of Pharmacy and Biochemistry, University of Zagreb, Zagreb, Croatia

3 Department of Medical Biochemistry and Hematology, Faculty of Pharmacy and Biochemistry, University of Zagreb, Zagreb, Croatia

4 Department of Biophysics, Faculty of Pharmacy and Biochemistry, University of Zagreb, Zagreb, Croatia

5 Mutagenesis Unit, Institute for Medical Research and Occupational Health, Zagreb, Croatia 